\title{
Quantificação do efeito benéfico de passagem inferior como barreira acústica
}

\author{
Adalice Flávia Duarte de Medeiros ${ }^{1}$, Roberto Leal Pimentel ${ }^{2}$, Ricardo Almeida de Melo ${ }^{3}$ \\ 1Programa de Pós-Graduação em Engenharia Civil e Ambiental, Universidade Federal da Paraíba, adalice_duarte@hotmail.com \\ 2Departamento de Engenharia Civil e Ambiental da UFPB, Universidade Federal da Paraíba, r.pimentel@uol.com.br \\ ${ }^{3}$ Departamento de Engenharia Civil e Ambiental da UFPB, Universidade Federal da Paraíba, ricardo@ct.ufpb.br
}

\section{Recebido: \\ 14 de março de 2018 \\ Aceito para publicação: \\ 27 de maio de 2018 \\ Publicado: \\ 4 de novembro de 2018 \\ Editor de área: \\ Bruno Vieira Bertoncini}

\section{Palavras-chaves:}

Ruído de tráfego;

Passagem inferior;

Barreira acústica.

Keywords:

Traffic noise;

Underpass;

Noise barrier.

DOI: 10.14295/transportes.v26i3.1622

\begin{abstract}
RESUMO
A utilização de barreiras acústicas é uma das medidas empregadas para minimizar o impacto gerado pelo ruído, pois é possível produzir uma atenuação no nível sonoro por meio da restrição à passagem do som diretamente da fonte para o receptor. As passagens inferiores em rodovias vêm sendo usadas para evitar cruzamentos em nível entre as vias. Pressupõe-se que esse desnível pode funcionar como uma barreira acústica contribuindo com a redução do ruído nas áreas circunvizinhas, com a vantagem de possuir pouco impacto visual. Neste artigo, analisou-se a passagem inferior construída na BR230 com o objetivo de quantificar o efeito benéfico da mesma em relação a redução do ruído emitido. Medições de ruído foram realizadas na área urbana adjacente a esta passagem e, com os resultados obtidos, foram feitas correlações com expressões do modelo CoRTN para estimativa do ruído. Verificou-se, por meio comparativo, os benefícios que a passagem inferior disporia como solução acústica. Como resultado, obteve-se uma redução média de $11,8 \mathrm{~dB}(\mathrm{~A})$, constituindo uma atenuação expressiva no nível de ruído para os pontos na região de sombra acústica.
\end{abstract}

\section{ABSTRACT}

The use of noise barriers is one of the measures employed to minimize the impact generated by noise due to the sound level attenuation produced by restricting the passage of sound directly from the source to the receiver. Below level segments of highways have being used to avoid at-level intersections between roads. It is assumed that this difference of level can act as an acoustic barrier, contributing to the reduction of noise in the surrounding areas without causing a substantial visual impact. In this paper, the underpass constructed in the BR-230 was analyzed in order to quantify the effect on the reduction of the emitted noise. This study, which involves local measurements and acoustic simulations using CoRTN's models, demonstrates the benefits that underpasses can provide as an acoustic solution. Comparing the estimated values without underpass with the on-site measurements, an average reduction of $11.8 \mathrm{~dB}(\mathrm{~A})$ was obtained. Underpasses can thus cause a significant attenuation in noise levels for locations in the acoustic shadow zone.

\section{INTRODUÇÃO}

Entre diversas fontes sonoras causadoras de ruído no meio urbano, dedica-se uma atenção especial ao ruído gerado pelos veículos automotivos, pois estes são os que provocam elevados índices de poluição sonora e estão diretamente associados ao crescimento acelerado das grandes cidades. Segundo Kyçyku et al. (2016), o ruído de tráfego domina com 50\% da emissão de ruído produzido pela totalidade de fontes sonoras no meio urbano.

0 ruído é reconhecido como um elemento de poluição ambiental, sendo capaz de provocar efeitos nocivos à saúde da população (Bistafa, 2006). Contudo, medidas para reduzir o nível de 
ruído são amplamente investigadas de pontos de vista diferentes, considerando origem, propagação e medidas mitigadoras (uso de barreiras, bermas, vegetação entre outros). Procura-se, portanto, intervenções no meio que possam diminuir a intensidade dos sons que atingem o receptor (Saliunas e Volkovas, 2015).

A utilização de barreiras acústicas é uma alternativa que pode trazer benefícios para o controle de ruído. 0 efeito de redução do nível de ruído pode ser estimado por modelos existentes na literatura, a exemplo das equações contidas no manual CoRTN (HMSO, 1988).

O desempenho de uma barreira acústica depende, dentre outros fatores, da sua forma. Investigações a respeito das diferentes formas, a saber, parâmetros como altura, espessura e detalhe do topo de uma barreira dão uma indicação da capacidade das barreiras acústicas de bloquear a transmissão de som (Yuzawa e Sone, 1981; Fujiwara et al., 1998; Kim e Yoon, 2015; Oldham e Egan, 2015; Kasess et al., 2016; Chobeau et al., 2017).

Este desempenho pode ser quantificado através de seus índices de difração e reflexão; Kurze e Anderson (1971) calcularam a atenuação sonora devido à difração e realizaram análises acerca de zonas iluminadas e zonas de sombra acústica, assim como Seznec (1980) que estudou o ruído difratado por barreiras de diferentes formatos. Quanto à reflexão, tem-se que May e Osman (1980) estudaram as configurações reflexivas de barreiras com geometrias diferentes, Crombie et al. (1995) analisaram uma maneira de minimizar o som refletido e Watts (1996) estudou o efeito do som refletido pela barreira oposta quando são usadas barreiras paralelas.

Salienta-se que o desempenho varia em função da geometria do local, altura e afastamento entre as barreiras e evidencia-se que o efeito de pares de barreiras acústicas, conhecidas como barreiras acústicas paralelas, nem sempre é benéfico, pois o efeito da barreira mais afastada é geralmente prejudicial à atenuação da barreira mais próxima (Watts, 1996).

Cabe salientar que passagens inferiores em rodovias evitam cruzamentos em nível entre as vias e, portanto, reduzem os conflitos de tráfego. Porém, o seu papel como barreira acústica que pode contribuir com a redução do nível de ruído, não tem sido devidamente investigado no Brasil.

A barreira acústica urbana, objeto deste estudo, é uma passagem inferior para via de tráfego intenso. Essa passagem inferior foi construída em meados dos anos 70, com o objetivo de dar lugar para a BR-230 atravessar uma área urbana existente. Tais passagens surgem como uma potencial solução para a minimização do ruído sem causar grandes impactos e ainda melhorar o conforto acústico das áreas adjacentes. Barreiras convencionais, de acordo com Arenas (2008), possuem algumas reações negativas tais como a perda de luz solar e o impacto visual. Além disso, Jiang e Kang (2016) mostram que as barreiras consideradas mais agradáveis esteticamente apresentaram pouca vantagem em alcançar um melhor desempenho acústico.

Neste contexto, o objetivo do trabalho foi avaliar o efeito benéfico da passagem inferior, do ponto de vista da redução do nível de ruído produzido por tráfego em vias expressas, visto que os muros de contenção da passagem podem funcionar como barreiras acústicas. Isto se deu por meio de medições do nível de ruído, correlações com modelos da literatura para estimativa do ruído e análise comparativa da redução do nível de ruído. Em trabalho anterior (Cavalcante et al., 2013), foi realizado um estudo inicial do efeito atenuante desta passagem inferior, a partir de medições realizadas, em alguns pontos, em via perpendicular à passagem. Tal estudo foi aqui expandido, procurando-se analisar vários pontos na área urbana adjacente, de modo a permitir melhor compreensão do efeito da redução do nível de ruído provocado pela passagem inferior, no conjunto da área urbanizada. 


\section{MÉTODO E APLICAÇÃO}

O delineamento da pesquisa se deu através de levantamentos de dados em campo e cálculo de estimativas de ruído através de equações definidas no manual do CoRTN (HMSO, 1988). 0 método de trabalho está representado no diagrama da Figura 1.

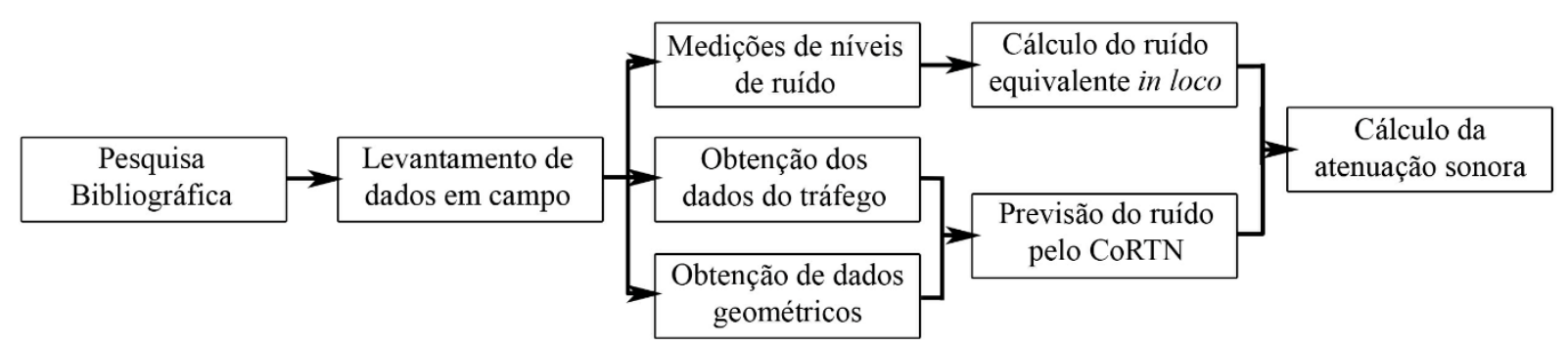

Figura 1: Procedimento adotado para obtenção da atenuação sonora estimada.

\section{1. Área de estudo e coleta de dados}

João Pessoa, capital do estado da Paraíba, está localizada na região nordeste do Brasil. De acordo com o censo demográfico de 2010, sua população era de 723.515 habitantes numa área de 211,475 $\mathrm{Km}^{2}$ (IBGE, 2018). A coleta de dados foi realizada no bairro Tambauzinho desta cidade. Tal bairro é predominante residencial e não possui uma verticalização intensa, abrigando uma população de classe média (vide Figura 2). Este local foi escolhido por possuir uma passagem inferior em desnível significativo com as áreas residenciais circunvizinhas (Figura 2).

A rodovia (BR-230) é composta por quatro faixas de tráfego, sendo duas para cada sentido que, juntamente com os acostamentos laterais e canteiro central, compreende uma largura de 22,41 metros entre as barreiras. 0 desnível entre as faixas de rodagem da rodovia e o pavimento das ruas adjacentes à passagem inferior é de 8,37 metros.

Para medir o nível de ruído foram utilizados medidores de nível de pressão sonora, sendo eles Minipa classe 2, modelos MSL-1354 e 1352-C, e B\&K classe 1 modelo 2250L. Adicionalmente, para as estimativas do ruído utilizando modelos da literatura, foi necessário obter dados de tráfego como fluxo, composição e velocidade média dos veículos que circulavam na BR-230. Para isso, utilizou-se um radar de velocidade portátil Bushnell e uma filmadora digital Sony modelo DCR-DVD610. Nas Figuras 3 e 4 pode-se observar o posicionamento do medidor de velocidade, da filmadora e dos pontos onde foram feitas as medições.

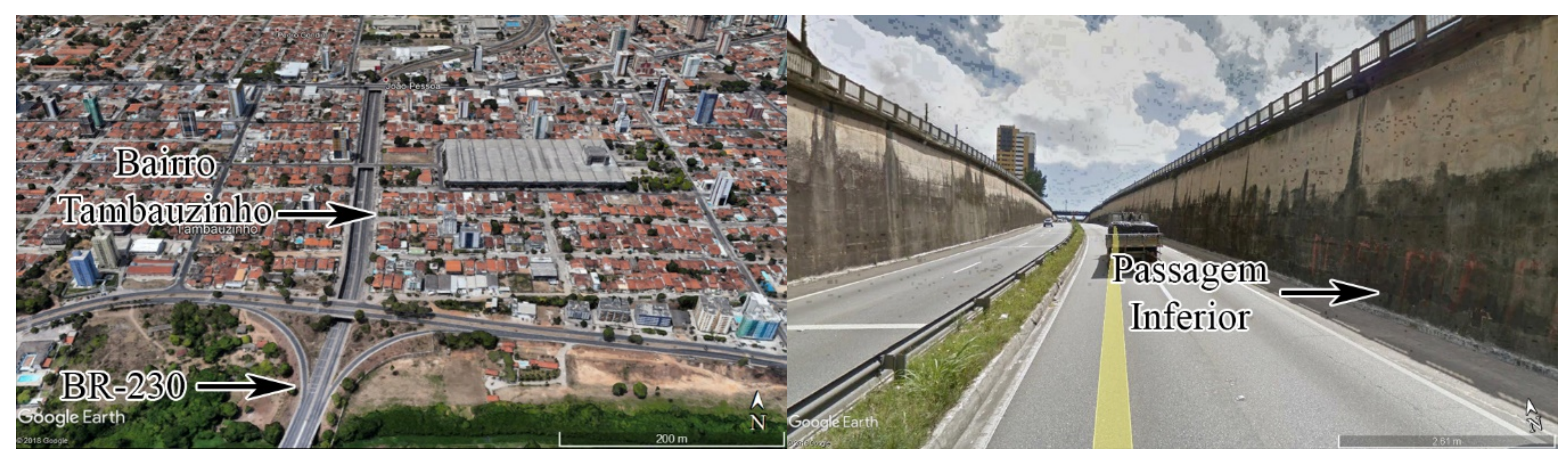

Figura 2: Vista da BR-230 que atravessa em desnível o bairro de Tambauzinho (Fonte: Google Earth) 


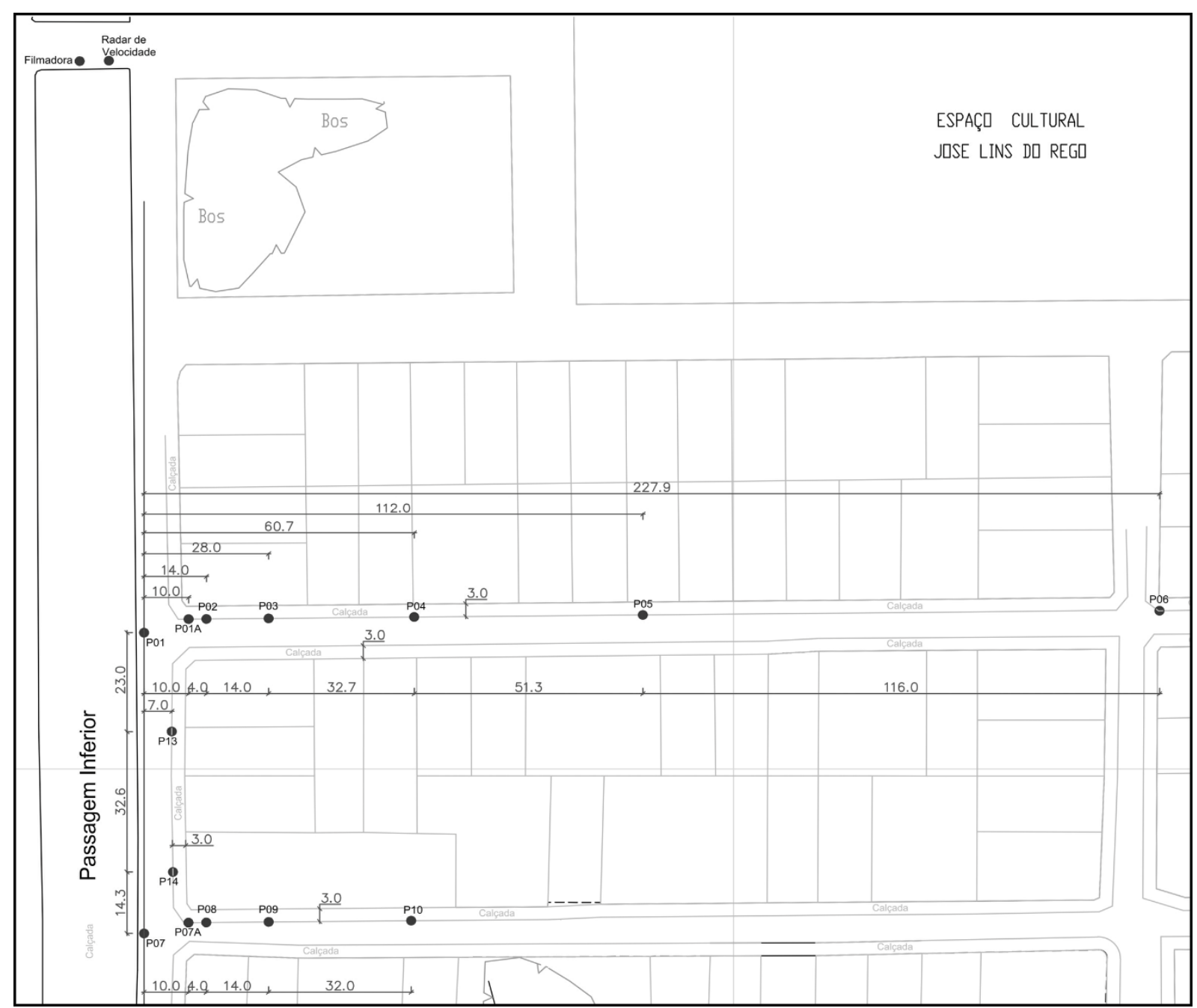

Figura 3: Pontos onde foram realizadas medições (medidas em metros).

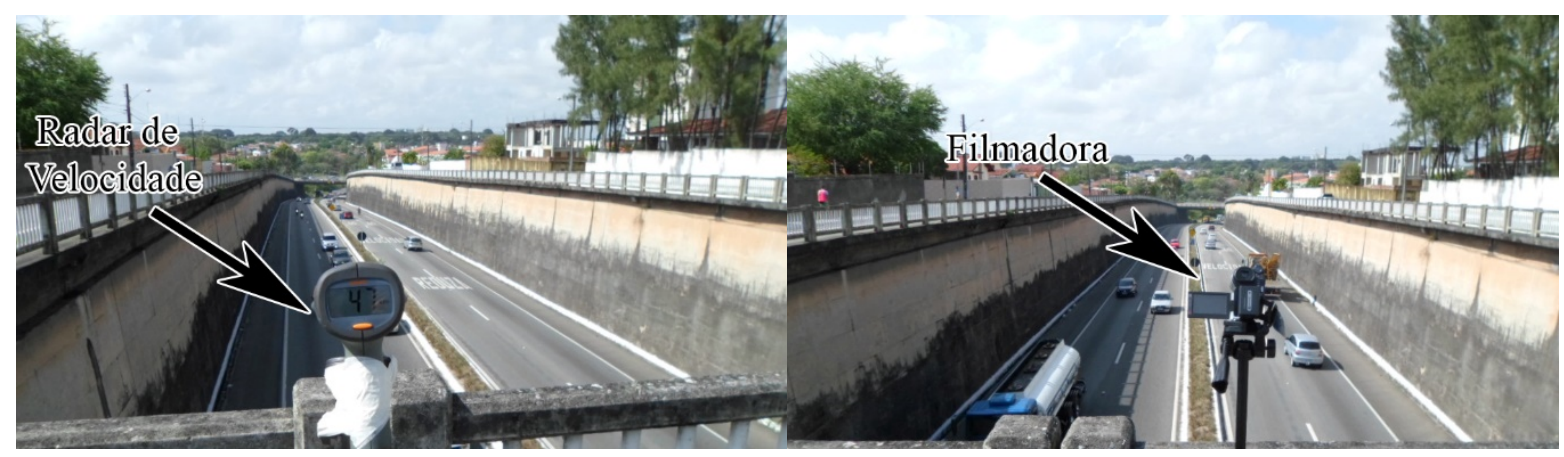

Figura 4: Vista do posicionamento do medidor de velocidade e da filmadora.

\subsection{Procedimentos para estimativas do nível de ruído}

Para estimar o nível de ruído, fez-se uso das equações do CoRTN (HMSO, 1988) para avaliar, inicialmente, o ruído proveniente da BR-230 sem a presença de barreiras acústicas e, posteriormente, o ruído com a presença de uma barreira acústica com atributos semelhantes ao da passagem inferior existente.

A estimativa realizada, utilizando o CoRTN, considera velocidades constantes de tráfego e faz uso de expressões matemáticas da propagação sonora, que levam em conta a atenuação devido as barreiras na propagação sonora. 
Tem-se, então, a Equação 1, que estima o nível de ruído em propagação plana sem obstruções (isto é, sem barreiras), para uma distância de 13,5 m entre a fonte sonora e o ponto de recepção:

$$
L_{10}=10 \log q+33 \log \left(v+40+\frac{500}{V}\right)+10 \log \left(1+\frac{5 p}{V}\right)-26,6(\mathrm{dBA})
$$

em que: $\quad q$ : fluxo de veículos em duas faixas de rodagem [veíc./h];

$v$ : velocidade média dos veículos $[\mathrm{km} / \mathrm{h}]$;

p: percentual de veículos pesados em relação ao tráfego total [\%];

L10: nível de ruído ultrapassado por $10 \%$ dos valores no intervalo de medição.

Os valores obtidos foram posteriormente convertidos para o nível de ruído equivalente $L_{e q}$, utilizando-se a relação entre $L_{10}$ e $L e q$ obtida das próprias medições.

A Equação 2 faz uma correlação para a distância entre a origem da fonte e o ponto de recepção, já que na Equação 1 o cálculo é realizado para uma distância de referência de 13,5 m.

$$
\Delta L=-10 \log \left(\frac{\sqrt{(d+3,5)^{2}+h^{2}}}{13,5}\right)
$$

em que: $d$ : é a distância entre o ponto de recepção e a borda da faixa de rolamento mais próxima $[\mathrm{m}]$;

$h$ : é a altura entre o ponto de recepção em relação à altura da fonte sonora; o modelo considera que a fonte sonora se encontra a $0,5 \mathrm{~m}$ do solo [m]

A Equação 3 relaciona a diferença de percurso devido a uma obstrução (Figura 5).

$$
\delta=S B+B R-S R
$$

em que: $\quad S B$ : distância entre a fonte de ruído e a borda da barreira [m];

$B R$ : distância entre a borda da barreira e o ponto de recepção [m];

$S R$ : distância entre a fonte de ruído e o ponto de recepção [m].

Vale salientar que, a correção (atenuação devido à difração da barreira próxima) será feita de formas diferentes no caso de o ponto de recepção estar na zona iluminada, Equação 4 (onde há contato visual entre o ponto de recepção e a fonte de ruído) e na zona de sombra acústica, Equação 5 (quando não há contato visual).

$$
\begin{aligned}
& \text { Correção } o_{z I}=0,109 x-0,815 x^{2}+0,479 x^{3}+0,3284 x^{4}+0,04385 x^{5} \\
& \text { Correçã } o_{z S}=-15,4-8,26 x-2,787 x^{2}-0,831 x^{3}-0,198 x^{4}+0,1539 x^{5}+0,12248 x^{6}+0,02175 x^{7}
\end{aligned}
$$

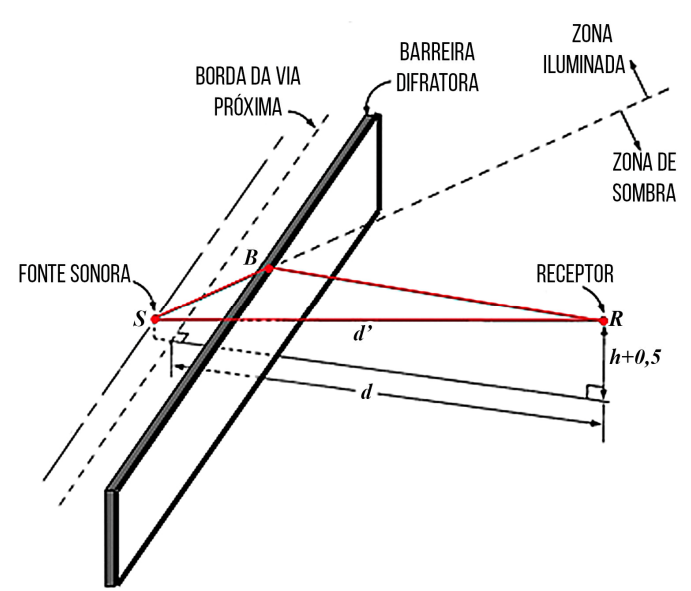

Figura 5: Diferença de percurso devido a uma obstrução. (Adaptado do HMSO (1988)) 
Nas Equações 4 e 5 considerar o estabelecido na Equação 6.

$$
x=\log \delta
$$

Para a correção da reflexão da barreira oposta, tem-se a formulação da Equação 7.

$$
\text { Correção }_{R F}=\{1,5+(\Delta 2-\Delta 3)[1+\Delta 5(\Delta 1-1)]\} \Delta 4
$$

Onde $\Delta 1$ é determinado a partir da altura do ponto de recepção e da altura da barreira de reflexão (Figura 6):

se $Y \geq W$ e $\alpha \geq W$, então $\Delta 1=W$

se $Y \geq W$ e $\alpha<W$, então $\Delta 1=\alpha$ e caso $\alpha<1$, então $\Delta 1=1$

se $Y<W$ e $\alpha \geq Y$, então $\Delta 1=Y$

se $Y<W$ e $\alpha<Y$, então $\Delta 1=\alpha$ e caso $\alpha<1$, então $\Delta 1=1$

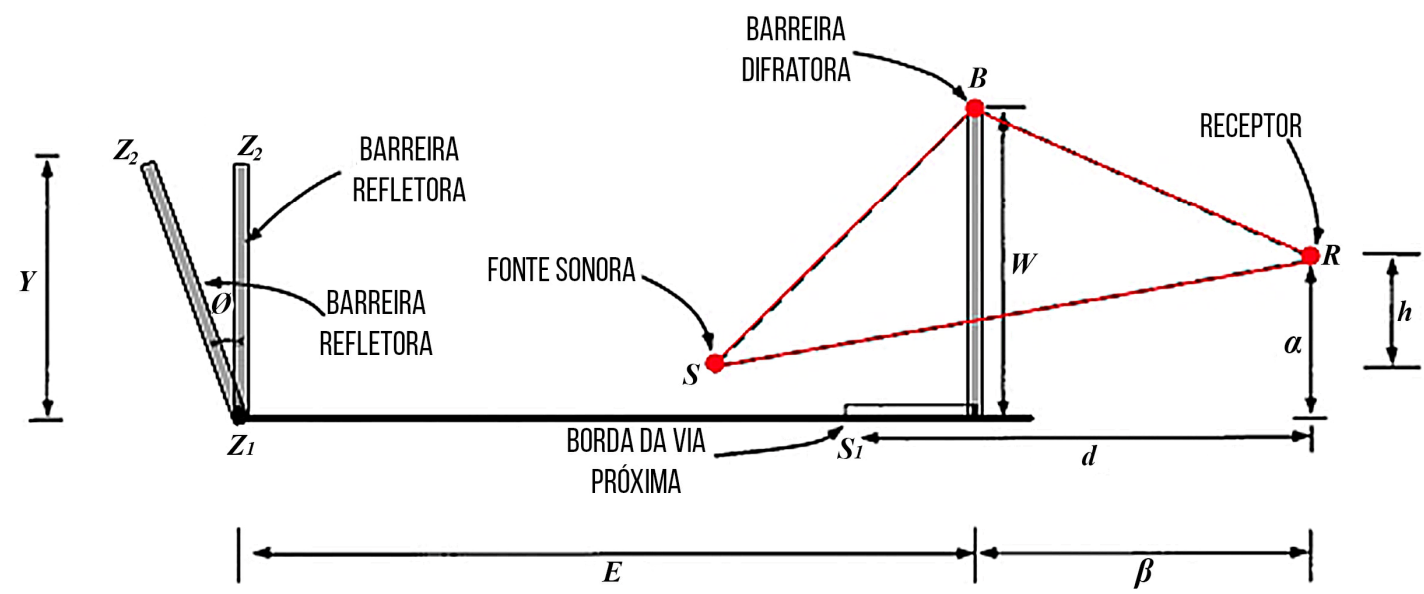

Figura 6: Geometria da barreira vertical, $\varnothing=0^{\circ}$. (Adaptado do HMSO (1988))

A partir do desenho esquemático na Figura 6, observa-se a necessidade de detalhar o significado de alguns dos parâmetros apresentados. Define-se:

$Y$ : altura da barreira de reflexão do ruído;

$S$ : fonte do ruído;

$E$ : largura entre as barreiras;

$B$ : borda superior da barreira mais próxima do receptor;

$R$ : ponto de recepção;

$W$ : altura da barreira mais próxima do receptor;

$d$ : distancia horizontal entre a borda da faixa de rodagem $S_{1}$ mais próxima e o ponto de recepção;

$h$ : distancia vertical entre a fonte de ruído e o ponto de recepção;

$\alpha$ : altura do ponto de recepção em relação ao pavimento da passagem inferior;

$\beta$ : distancia horizontal entre o ponto de recepção e a borda superior da barreira;

$z 1-z 2$ : barreira de reflexão do ruído.

Para determinar $\Delta 2$ e $\Delta 3$, tem-se as Equações 8 e 9 .

em que: $\quad$ se $\alpha<0$, então $\Delta 2=0,2$

$$
\Delta 2=[8,2-3 \log (\alpha+10)] \cdot \log (\alpha+10)-5
$$

se $\alpha>30$, então $\Delta 2=0,44$ 
em que: $\quad$ se $\beta<10$, então $\Delta 3=+0,06$

$$
\Delta 3=\left[1-0,6 \log \left(35+\frac{\beta}{2}\right)\right] \cdot \log \left(35+\frac{\beta}{2}\right)
$$

se $\beta>80$, então $\Delta 3=-0,23$

Para obter o $\Delta 4$, o mesmo é determinado a partir da distância horizontal $E$ entre as barreiras (Equação 10):

em que: $\quad$ se $E<30$, então $\Delta 4=1$

$$
\Delta 4=\log \left[1+\left(\frac{270}{E}\right)\right]
$$

se $E>70$, então $\Delta 4=0,69$

Por fim, $\Delta 5$ é determinado em função do ângulo $\emptyset$, que é o ângulo entre a barreira e uma linha perpendicular ao solo. Como para o caso em estudo, a barreira não é inclinada, tem-se $\emptyset=0^{\circ}$, resultando na Equação 11:

$$
\Delta 5=e^{\left(-0,019 \emptyset^{2}\right)}
$$

Ao realizar estimativas de ruído é preciso considerar alguns aspectos, quais sejam, o fluxo de veículos, características geométricas das vias, correções devido à declividade da pista, velocidade média real dos veículos, porcentagem de veículos pesados, dentre outros (Nunes e Santos, 1998). Os dados provenientes do tráfego foram coletados in loco e usados para o cálculo estimado do ruído de tráfego, com o uso das equações descritas anteriormente.

Para a obtenção dos dados do volume do tráfego foi realizada, simultaneamente com as medições de nível de ruído, uma filmagem durante uma hora das quatro faixas de rodagem da BR230. A partir das imagens capturadas na filmagem, foram realizadas a contagem do tráfego para cada faixa e para cada tipo de veículo (automóveis, motocicletas e veículos pesados).

Para obtenção dos dados de velocidade foi utilizado radar. 0 procedimento consistiu em permanecer cinco minutos em cada faixa, durante uma hora e proceder a captura da velocidade do maior número possível de veículos de cada tipo. 0 procedimento padrão para a medição de velocidade é de capturar a velocidade estando de frente e no mesmo nível do veículo. Como não havia viabilidade em estar no mesmo nível dos veículos, procedeu-se com a medição posicionado em viaduto existente acima da BR-230 (vide Figura 3) e então fez-se uma correção da velocidade. Para tal correção, realizou-se um procedimento que consistiu em utilizar um veículo trafegando na via com uma velocidade predefinida e observando qual a leitura feita pelo radar de velocidade; com esses dados obteve-se uma expressão para a correção da velocidade (Equação 12).

$$
V_{\text {corrigida }}=\frac{V_{\text {Medida }}}{0,89}
$$

\subsection{Cálculo do ruído equivalente "in loco"}

Para a medição do nível de ruído, os medidores de nível sonoro foram acoplados em tripés a uma altura padrão estipulada em 1,30 m; posicionados a uma distância mínima de 2,00 m em relação a muros, bem como distantes de árvores ou qualquer outro tipo de obstrução.

As medições foram realizadas em um período de uma hora, sendo que, a coleta de dados foi feita durante cinco minutos e com intervalo de 10 minutos entre as coletas; logo foram feitas quatro coletas de cinco minutos durante o período de uma hora. Este procedimento já havia 
sido verificado ser adequado na medição do ruído, com pequena flutuação entre as coletas (Cavalcante et al., 2013).

Por fim, a média desses valores para cada ponto foi calculada segundo a Equação 13, salientase que a quantidade de leituras foi variável, de forma a expurgar fontes espúrias de ruído, tais como latido de cães ou outras fontes que não as devido ao tráfego de veículos na via em estudo.

$$
L A_{e q}=10 \log \frac{1}{n} \sum_{i=1}^{n} 10^{L_{i} / 10}
$$

em que: $\quad L A_{e q}$ : nível de pressão sonora equivalente em decibel $(\mathrm{A})[\mathrm{dB}(\mathrm{A})]$;

$L_{i}$ : leituras do nível de pressão sonora, em $\mathrm{dB}(\mathrm{A})$;

$n=$ número total de leituras.

\section{RESULTADOS E DISCUSSÃO}

Por meio das medições de campo do ruído para os 14 pontos, foram obtidos os valores de nível de pressão sonora, para cada uma das quatro medições no intervalo de uma hora. Após, foi calculado o nível de pressão sonora equivalente. Os resultados obtidos estão na Tabela 1. Deve-se notar que em todos os dias, foi sempre medido o nível de ruído no ponto P01, conforme discutido adiante. Para localização dos pontos, vide Figura 2.

Tabela 1: Nível de pressão sonora para os 14 pontos

\begin{tabular}{|c|c|c|c|c|c|}
\hline \multicolumn{6}{|c|}{ Dia 1} \\
\hline Medições dB(A) & $B \& K(P 01)$ & Minipa (P02) & Minipa (P03) & \multicolumn{2}{|l|}{ Minipa (P04) } \\
\hline $1^{\circ}$ Medição (início às 08:45 h) & 77,80 & 63,44 & 59,05 & \multicolumn{2}{|l|}{53,69} \\
\hline $2^{\circ}$ Medição (início às 09:00 h) & 77,80 & 61,98 & 58,47 & \multicolumn{2}{|l|}{52,85} \\
\hline $3^{\circ}$ Medição (início às 09:15 h) & 78,10 & 62,55 & 59,22 & \multicolumn{2}{|l|}{51,91} \\
\hline $4^{\circ}$ Medição (início às 09:30 h) & 77,70 & 62,51 & 58,30 & \multicolumn{2}{|l|}{52,19} \\
\hline LAeq (1h) & 77,9 & 62,6 & 58,8 & \multicolumn{2}{|l|}{52,7} \\
\hline \multicolumn{6}{|c|}{ Dia 2} \\
\hline Medições dB(A) & $B \& K(P 01)$ & Minipa (P01A) & Minipa (P05) & \multicolumn{2}{|l|}{ Minipa (P06) } \\
\hline $1^{\circ}$ Medição (início às 08:45 h) & 78,20 & 65,24 & 49,10 & \multicolumn{2}{|l|}{50,27} \\
\hline $2^{\circ}$ Medição (início às 09:00 h) & 79,10 & 64,51 & 49,31 & \multicolumn{2}{|l|}{48,67} \\
\hline $3^{\circ}$ Medição (início às 09:15 h) & 78,00 & 65,51 & 48,62 & \multicolumn{2}{|l|}{50,07} \\
\hline $4^{\circ}$ Medição (início às 09:30 h) & 77,30 & 64,73 & 47,71 & \multicolumn{2}{|l|}{49,64} \\
\hline LAeq (1h) & 78,2 & 65,0 & 48,7 & \multicolumn{2}{|l|}{49,7} \\
\hline \multicolumn{6}{|c|}{ Dia 3} \\
\hline Medições dB(A) & $\mathrm{B} \& \mathrm{~K}(\mathrm{P} 01)$ & Minipa (P13) & Minipa (P14) & \multicolumn{2}{|l|}{ Minipa (P07A) } \\
\hline $1^{\circ}$ Medição (início às 08:40 h) & 78,20 & 67,96 & 68,55 & \multicolumn{2}{|l|}{64,99} \\
\hline $2^{\circ}$ Medição (início às 08:55 h) & 78,30 & 68,25 & 68,60 & \multicolumn{2}{|l|}{65,48} \\
\hline $3^{\circ}$ Medição (início às 09:10 h) & 77,70 & 67,82 & 67,51 & \multicolumn{2}{|l|}{64,35} \\
\hline $4^{\circ}$ Medição (início às 09:25 h) & 78,40 & 68,07 & 68,24 & \multicolumn{2}{|l|}{64,98} \\
\hline LAeq (1h) & 78,2 & 68,0 & 68,2 & \multicolumn{2}{|l|}{65,0} \\
\hline \multicolumn{6}{|c|}{ Dia 4} \\
\hline Medições dB(A) & $\mathrm{B} \& \mathrm{~K}(\mathrm{P} 01)$ & Minipa (P07) & Minipa (P08) & Minipa (P09) & Minipa (P10) \\
\hline $1^{\circ}$ Medição (início às 08:20 h) & 78,50 & 78,77 & 64,39 & 58,60 & 52,74 \\
\hline $2^{\circ}$ Medição (início às 08:35 h) & 78,80 & 78,89 & 64,40 & 58,24 & 51,77 \\
\hline $3^{\circ}$ Medição (início às 08:50 h) & 78,50 & 78,78 & 64,50 & 57,88 & 51,72 \\
\hline $4^{\circ}$ Medição (início às 09:05 h) & 78,00 & 78,34 & 63,48 & 58,06 & 51,21 \\
\hline LAeq $(1 \mathrm{~h})$ & 78,5 & 78,7 & 64,2 & 58,2 & 51,9 \\
\hline
\end{tabular}

A partir da Tabela 1, observa-se que, na proporção que os pontos medidos se afastam da passagem inferior, o ruído captado pelo decibelímetro diminui. Constata-se, também, que os pontos equidistantes possuem níveis de pressão sonora semelhantes. 
Concomitantemente à medição de ruído, foram obtidos dados de tráfego como composição, velocidade $(v)$ e fluxo de veículos $(q)$ e o percentual de veículos pesados em relação ao fluxo total $(p)$; os dados estão apresentados na Tabela 2.

Tabela 2: Caracterização do tráfego

\begin{tabular}{|c|c|c|c|c|c|}
\hline \multicolumn{3}{|c|}{ Dia 1} & \multicolumn{3}{|c|}{ Dia 2} \\
\hline Variáveis & Faixa 1 e 2 & Faixa 3 e 4 & Variáveis & Faixa 1 e 2 & Faixa 3 e 4 \\
\hline$q$ & 2543 & 2530 & $q$ & 2378 & 2506 \\
\hline $\mathrm{v}(\mathrm{km} / \mathrm{h})$ & 68,35 & 75,65 & $v(\mathrm{~km} / \mathrm{h})$ & 69,74 & 73,46 \\
\hline$p(\%)$ & $7,27 \%$ & $6,92 \%$ & $p(\%)$ & $5,63 \%$ & $5,35 \%$ \\
\hline \multicolumn{3}{|c|}{ Dia 3} & Dia 4 & & \\
\hline Variáveis & Faixa 1 e 2 & Faixa 3 e 4 & Variáveis & Faixa 1 e 2 & Faixa 3 e 4 \\
\hline$q$ & 2373 & 2606 & $q$ & 2488 & 2748 \\
\hline$v(\mathrm{~km} / \mathrm{h})$ & 71,78 & 78,62 & $v(\mathrm{~km} / \mathrm{h})$ & 72,34 & 74,94 \\
\hline$p(\%)$ & $6,36 \%$ & $6,02 \%$ & $p(\%)$ & $5,39 \%$ & $4,91 \%$ \\
\hline
\end{tabular}

A partir dos dados de tráfego apresentados, estimou-se o nível de pressão sonora equivalente seguindo as etapas de cálculo elencadas nos itens 2.2. e 2.3. Primeiro, foi realizado o cálculo da estimativa de ruído desconsiderando o efeito da passagem inferior e, em seguida, considerando a obstrução (difração) da barreira mais próxima e a reflexão da barreira mais afastada.

Para permitir uma avaliação conjunta do efeito da barreira simultaneamente em todos os pontos, os resultados foram homogeneizados. Para isso tomou-se como referência o ponto P01 e dele foram coletados dados em todas as medições. A homogeneização foi feita como segue: calculou-se a diferença dos valores obtidos para o ponto P01 no primeiro dia de medição em relação aos valores obtidos para este mesmo ponto em cada um dos demais dias; essa diferença foi somada (ou subtraída, conforme aplicável) ao valor de cada um dos outros pontos.

Os resultados obtidos para difração e reflexão podem ser visualizados na Tabela 3. Nela podese observar que a medida que a distância aumenta tanto a difração da barreira próxima quanto a reflexão da barreira afastada aumentam. Salienta-se que para os pontos situados sobre a barreira a difração da barreira próxima é, aproximadamente, nula.

Tabela 3: Correções em dB(A) para difração e reflexão

\begin{tabular}{llll}
\hline Ponto - Distância & Difração & Reflexão & Resultante \\
\hline P01 - 0 m & $-0,2$ & 5,9 & $+5,7$ \\
P07 - 0 m & $-0,2$ & 5,9 & $+5,7$ \\
P13-7 m & $-12,3$ & 6,2 & $-6,1$ \\
P14-7 m & $-12,3$ & 6,2 & $-6,1$ \\
P01A-10 m & $-13,6$ & 6,3 & $-7,3$ \\
P07A - 10 m & $-13,5$ & 6,3 & $-7,3$ \\
P02-14 m & $-14,5$ & 6,4 & $-8,1$ \\
P08-14 m & $-14,7$ & 6,5 & $-8,2$ \\
P03-28 m & $-16,0$ & 7,0 & $-9,0$ \\
P09-28 m & $-16,0$ & 7,0 & $-9,0$ \\
P10-60 m & $-17,3$ & 8,3 & $-9,0$ \\
P04-60.7 m & $-16,6$ & 8,0 & $-8,6$ \\
P05-112 m & $-17,2$ & 9,7 & $-7,5$ \\
P06-227.9 m & $-17,6$ & 12,5 & $-5,1$ \\
\hline
\end{tabular}

Na Tabela 4, bem como na Figura 7, são apresentados os resultados finais mostrando de forma sequenciada os valores obtidos para o nível de pressão sonora prevista sem a passagem 
inferior, prevista com a passagem inferior e real com passagem inferior. Calculou-se o erro, ou seja, a variação entre o valor previsto e real com a passagem inferior. Por fim, foi calculado o valor da possível atenuação, isto é, a diferença entre o nível de pressão sonora com a passagem inferior e o mesmo sem a passagem inferior.

Tabela 4: Comparação de todos os LAeq em $\mathrm{dB}(\mathrm{A})$ previstos e reais

\begin{tabular}{llllll}
\hline & $\mathbf{( 1 )}$ & $\mathbf{( 2 )}$ & $\mathbf{( 3 )}$ & $\mathbf{( 2 )}-\mathbf{( 3 )}$ & $\mathbf{( 3 )}-\mathbf{( 1 )}$ \\
\cline { 2 - 6 } Ponto - Distância & $\begin{array}{l}\text { Previsto } \\
\text { sem passagem } \\
\text { inferior }\end{array}$ & $\begin{array}{l}\text { Previsto } \\
\text { com passagem } \\
\text { inferior }\end{array}$ & $\begin{array}{l}\text { Real } \\
\text { com passagem } \\
\text { inferior }\end{array}$ & $\begin{array}{l}\text { Erro } \\
\text { previsto com } \\
\text { passagem } \\
\text { inferior }\end{array}$ & $\begin{array}{l}\text { Atenuação } \\
\text { prevista vs. real }\end{array}$ \\
\hline P01-0 m & 77,1 & 82,8 & 77,9 & $+4,9$ & $+0,8$ \\
P07-0 m & 76,2 & 81,9 & 78,1 & $+3,8$ & $+1,9$ \\
P13-7 m & 74,3 & 68,2 & 67,7 & $+0,5$ & $-6,6$ \\
P14-7 m & 73,5 & 67,4 & 67,9 & $-0,5$ & $-5,6$ \\
P01A-10 m & 73,2 & 65,9 & 64,7 & $+1,2$ & $-8,5$ \\
P07A-10 m & 73,1 & 65,8 & 64,7 & $+1,1$ & $-8,4$ \\
P02-14 m & 71,7 & 63,6 & 62,6 & $+1,0$ & $-9,1$ \\
P08-14 m & 72,3 & 64,1 & 63,6 & $+0,5$ & $-8,7$ \\
P03-28 m & 69,5 & 60,5 & 58,8 & $+1,7$ & $-10,7$ \\
P09-28 m & 69,4 & 60,4 & 57,6 & $+2,8$ & $-11,8$ \\
P10-60 m & 68,0 & 59,0 & 51,3 & $+7,7$ & $-16,7$ \\
P04-60.7 m & 65,4 & 56,8 & 52,7 & $+4,1$ & $-12,7$ \\
P05-112 m & 63,8 & 56,3 & 48,5 & $+7,9$ & $-15,3$ \\
P06-227.9 m & 61,4 & 56,3 & 49,4 & $+6,9$ & $-12,0$ \\
\hline
\end{tabular}

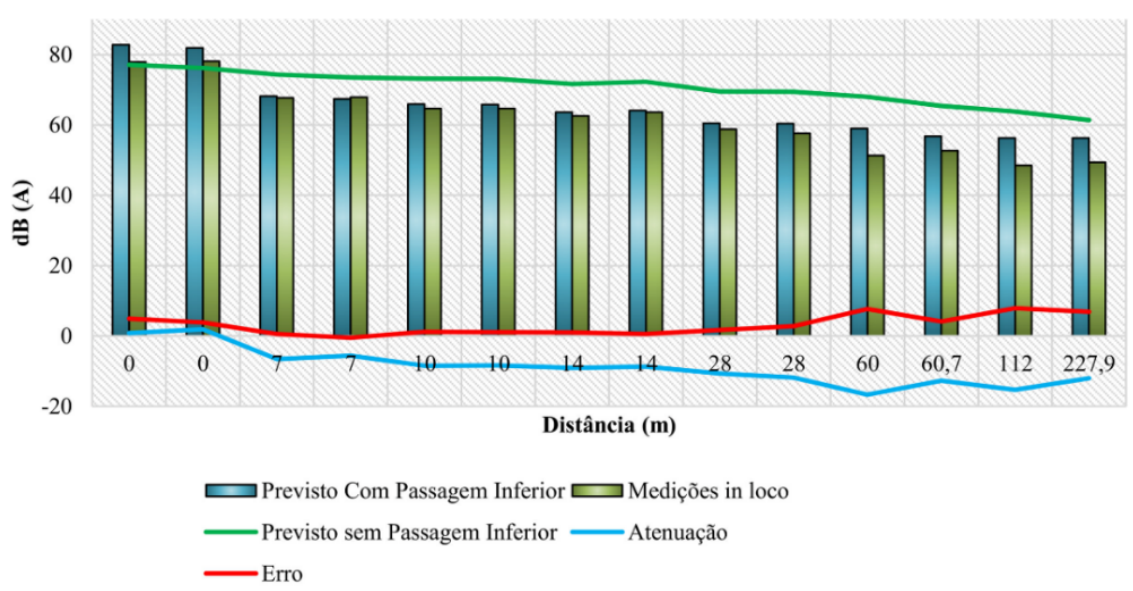

Figura 7: Gráfico comparando todos os LAeq em dB(A) previstos, reais, atenuação e o erro

Comparando as estimativas feitas com o modelo CoRTN e os valores medidos em campo considerando a passagem inferior, constata-se que o modelo superestima o ruído, principalmente para pontos próximos da borda da passagem inferior e para os pontos mais afastados.

Os pontos intermediários (entre a borda e $28 \mathrm{~m}$ ) apresentaram menores erros, entre 0,5 $\mathrm{dB}(\mathrm{A})$ e 2,8 dB(A); já os pontos situados nas bordas apresentaram erros de em média 4,4 dB(A) e os pontos muito distantes (a partir de 60,7 $\mathrm{m}$ da borda) tiveram variações na ordem de 4,1 $\mathrm{dB}(\mathrm{A})$ a $7,9 \mathrm{~dB}(\mathrm{~A})$.

Uma explicação para essas maiores variações em pontos mais afastados são que as expressões do CoRTN não levam em consideração a forma urbana ao redor dos pontos de recepção, ou seja, não levam em consideração as edificações no entorno e consideram que todos os pontos de recepção estão em um mesmo nível, sem levar em conta a topografia do terreno. 
Outra justificativa, para os pontos próximos à barreira, vem do fato da existência de uma saliência no topo da barreira (Figuras 3 e 4) que não é considerada nas expressões do CoRTN; esta saliência pode contribuir para reduzir a parcela do ruído que difrata na barreira minimizando as diferenças entre os níveis de ruído medidos e previstos. A literatura mostra que a forma do topo da barreira pode contribuir para a atenuação do ruído, podendo ser ainda maior como no caso em estudo. A atenuação do nível de ruído pode variar de $2 \mathrm{~dB}$ para $0,5 \mathrm{~m}$ até $4 \mathrm{~dB}$ para 2,5 m (Combrie et al., 1995; Ishizuka e Fujiwara, 2004; Bistafa 2006).

A partir dos valores obtidos na Tabela 3, observa-se que a difração da barreira mais próxima teve um efeito mais preponderante no nível de ruído. Verificou-se, também, que a parcela de reflexão da barreira oposta varia em menor proporção que a de difração e os pontos em zona iluminada são os mais afetados pela reflexão, pois nestes pontos a difração da barreira próxima é muito baixa. Em suma, quanto mais distante for o ponto de recepção da borda da passagem inferior, maior será o efeito benéfico da mesma.

Quando comparadas as estimativas de ruído sem a passagem inferior com os níveis de ruído medidos com a passagem inferior, pode-se obter uma atenuação média, apenas nos pontos em sombra acústica, de 11,8 dB(A). Confirma-se, assim, a eficiência da passagem inferior como uma solução para a minimização do ruído de tráfego em áreas residenciais.

\section{CONSIDERAÇÕES FINAIS}

Utilizaram-se predições acústicas empregando as expressões do modelo CoRTN, onde o nível de ruído foi estimado em dois cenários: sem e com a passagem inferior. Para o cenário com a passagem inferior, estimou-se o ruído considerando a difração devido à barreira mais próxima e a reflexão devido à barreira oposta. Foram confrontados os valores previstos com os medidos, e pode-se constatar que a passagem inferior produziu uma atenuação sonora para os pontos situados na zona de sombreamento acústico e uma amplificação nos pontos situados na zona iluminada. Este efeito de amplificação nesta zona aconteceu devido ao fato da parcela de reflexão da barreira oposta ser maior do que a parcela de difração da barreira próxima, visto que esses pontos estão encostados na barreira. Ao contrário, nos pontos situados na zona de sombra acústica, a obstrução da primeira barreira tem um efeito mais proeminente no nível de pressão sonora do que a reflexão da barreira mais distante, resultando em atenuação global do ruído. Com a passagem inferior, os pontos situados na zona de sombra acústica apresentaram uma redução média de 11,8 dB(A). Este valor foi obtido a partir da diferença entre as estimativas de ruído sem a passagem inferior e os valores medidos do nível de ruído. Constatou-se também que, via de regra, a atenuação do nível de ruído é crescente com a distância entre a borda da passagem inferior e o ponto de recepção.

Desta forma, a passagem inferior causa uma atenuação significativa no nível de ruído, confirmando a sua eficiência como uma solução para a minimização do ruído de tráfego em áreas residenciais. Salienta-se ainda que, além de ser quantitativamente eficiente em termos de redução do nível de ruído, é uma barreira acústica que não provoca um impacto visual muito grande nas regiões circunvizinhas.

Por fim, os resultados também mostram que os valores previstos pelas expressões do modelo CoRTN superestimam os valores de ruído e isso pode ser explicado devido a deficiência das expressões em não considerarem a forma urbana ao redor dos pontos de recepção nem a forma do topo da barreira. 


\section{AGRADECIMENTOS}

Os autores agradecem apoio financeiro da CAPES e a todas as pessoas que ajudaram na coleta de dados.

\section{REFERÊNCIAS}

Arenas, J.P. (2008) Potential problems with environmental sound barriers when used in mitigating surface transportation noise. Science of the Total Environment, Vol. 405, pp. 173-179. DOI: 10.1016/j.scitotenv.2008.06.049

Bistafa, S.R. (2006) Acústica aplicada ao controle de ruído. Ed. Edgard Blucher, São Paulo, 368 p.

Cavalcante, B.V.L.; R.L. Pimentel; R.A. Melo; C.A.A. Araújo; R.G. Sousa; J.R. Gonçalves e R.M. Menezes (2013) Avaliação do efeito de passagem inferior na redução de ruído de tráfego. In: XXVII ANPET - Congresso de Pesquisa e Ensino em Transportes, 2013, Belém. Anais... V. 1. p. 1-11.

Chobeau, P.; G. Guillaume; J. Picaut; D. Ecotière e G. Dutilleux (2017) A Transmission Line Matrix model for sound propagation in arrays of cylinders normal to an impedance plane. Journal of Sound and Vibration, V. 389, pp. 454-467. DOI: 10.1016/j.jsv.2016.11.005

Crombie, D.H; D.C. Hothersall e S.N. Chandler-Wilde (1995) Multiple-Edge Noise Barriers. Applied Acoustics, Vol. 44, pp. 353367. DOI: 10.1016/0003-682X(94)00032-Q

Fujiwara K.; D.C. Hothersall e C. Hwan Kim (1998) Noise barriers with reactive surfaces. Applied Acoustics, Vol. 53, n. 4, pp. 255-72. DOI: 10.1016/S0003-682X(97)00064-9

HMSO (1988) Calculation of Road Traffic Noise. Department of Transport. London: Her Majesty's Stationery Office. 94 p.

IBGE (2018) Banco de dados: Cidades. Instituto Brasileiro de Geografia e Estatística. Disponível em: $<$ https://cidades.ibge.gov.br/>. (Acesso em 20/02/2018)

Ishizuka, T. e K. Fujiwara (2004) Performance of noise barriers with various edge shapes and acoustical conditions. Applied Acoustics, Vol. 65, pp. 125-141. DOI: 10.1016/j.apacoust.2003.08.006

Jiang, L. e J. Kang (2016) Combined acoustical and visual performance of noise barriers in mitigating the environmental impact of motorways. Science of the Total Environment, Vol. 543, pp. 52-60. DOI: 10.1016/j.scitotenv.2015.11.010

Kasess, C.H.; W. Kreuzer e H. Waubke (2016) Deriving correction functions to model the efficiency of noise barriers with complex shapes using boundary element simulations. Applied Acoustics, Vol. 102, pp. 88-99. DOI: 10.1016/j.apacoust.2015.09.009

Kim K.H. e G.H. Yoon (2015) Optimal rigid and porous material distributions for noise barrier by acoustic topology optimization. Journal Sound Vibration, Vol. 339, pp. 123-42. DOI: 10.1016/j.jsv.2014.11.030

Kurze, U.J. e G.S. Anderson (1971) Sound attenuation by barriers. Applied Acoustics, Vol. 4, Issue 1, pp. 35-53. DOI: 10.1016/0003-682X(71)90024-7

Kyçyku, A.; S. Lajqi e G. Hoxha (2016) Analytical Calculation of Vehicles Noise in the Road Traffic and Graphical Presentation. IFAC-PapersOnLine, V. 49, Issue 29, pp. 52-57. DOI: 10.1016/j.ifacol.2016.11.075

May, D.N. e M.M Osman (1980) The performance of sound absorptive, reflective, and T-profile noise barriers in Toronto. Journal of Sound and Vibration, V. 71, Issue 1, pp. 65-71. DOI: 10.1016/0022-460X(80)90409-5

Nunes, M.F.O. e J.P. Santos (1998). Estudo do ruído de tráfego veicular urbano em Santa Maria. In: Congresso Iberoamericano de acústica, simpósio de metrologia e normalização em acústica e vibrações do Mercosul, 1998, Florianópolis.

Oldham, D.J. e C.A. Egan (2015) A parametric investigation of the performance of multiple edge highway noise barriers and proposals for design guidance. Applied Acoustics, Vol. 96, pp. 139-52. DOI: 10.1016/j.apacoust.2015.03.012

Saliunas, D. e V. Volkovas (2015) Investigation of noise barriers enhancement efficiency for attenuation of low frequency traffic noise. MECHANIKA, Vol. 21, pp. 56-63. DOI: 10.5755/j01.mech.21.1.10137

Scholes, W. E.; A.C. Salvidge e J.W. Sargent (1971) Field Performance of a Noise Barrier. Journal of Sound and Vibration, V. 16, pp. 627-642. DOI: 10.1016/0022-460X(71)90668-7

Seznec, R. (1980) Diffraction of sound around barriers: Use of the boundary elements technique. Journal of Sound and Vibration, V. 73, Issue 2, pp. 195-209. DOI: 10.1016/0022-460X(80)90689-6

Watts, G.R. (1996) Acoustic Performance of Parallel Traffic Noise Barriers. Applied Acoustics, V. 47, n.2, pp. 95-l19. Yuzawa, M.; Sone, T. (1981). Noise reduction by various shapes of barrier. Applied Acoustics, V. 14, n. 1, pp. 65-73. DOI: 10.1016/0003-682X(95)00031-4 